\title{
INVESTIGATION ON EFFECT OF SHADE PERCENTAGE ON COLOR FASTNESS OF VISCOSE FABRIC DYED WITH REACTIVE DYES (TURQUOISE COLOR)
}

\author{
ARIFUL ISLAM $^{1}$, SHAHINUL EMON $^{2} \&$ MUHAMMAD HOSSAIN KHAN $^{3}$ \\ ${ }^{I}$ Executive Engineer, Department of Wet Processing Engineering, Pabna Textile Engineering College, \\ Bangladesh University Of Textiles, Bangladesh \\ ${ }^{2}$ Student in Textile Engineering, Apparel Manufacturing Engineering, Pabna Textile Engineering College, \\ Rajshahi University, Bangladesh \\ ${ }^{3}$ Executive Engineer, Wet Processing Engineering, Ahsanullah University, Bangladesh
}

\begin{abstract}
Textile is a wide sector in the world now-a-days. It divided into different sections and has developed different properties. Textile fabric contains some essential properties. Color fastness is a vital property among the all textile fabric properties. It is the resistance of the textile materials or goods for resisting against various destructive factors like Light, wearing, abrasion, heat, water and wash with detergents, acid and like so on. Color fastness means the resistance of color to be bleed with others or fade of colored material both of printed or solid dyed to various kinds of influences like rubbing, perspiration, light, water, washing with detergents or others washing agents and others which phenomenon are carried out in daily basis with textile materials. This study concerns with the effect of shade percentage on the color fastness of viscose fabric dyed with reactive dyes like color fastness to wash, color fastness to light, color fastness to perspiration and color fastness to rubbing.
\end{abstract}

KEYWORDS: Viscose Fabric, Chemicals \& Auxiliaries, Reactive Dyes, Shade Depth \& Color Fastness

Received: May 10, 2019; Accepted: May 30, 2019; Published: Oct 03, 2019; Paper Id.: IJTFTDOCT20192

\section{INTRODUCTION}

Now-a-days textile is one of the top most covered business area in all over the world and also improving its market rapidly day-by-day. The end users of the textile materials or goods are being well conscious about those products which are they getting and sourcing something new and much more improved quality of product they have. Now-a-days it becomes the high challenge for the manufacturer for obtaining the profit amount which they earned before. Because as one side it is being essential to improve the quality of the product, on the other hand they faced a great challenge to reduce the product price. They are trying to modify their process to obtain the profit and getting output with better quality product. In my research, I clearly described the present and latest standard working procedures and methods for evaluating and testing the color fastness of the textile materials viscose fabric and deduce a vital relation between the depth of shade and various types of color fastness. In case of viscose fabric it has a great effect of shade depth on color fastness.

Viscose is the oldest fiber and it is a regenerated cellulose fiber from wood pulp which shows a wide range of diverse property. Cellulosic substances are abundantly used natural polymer in worldwide. Because, it is really very eco-friendly, biodegradable and easily renewable polymer. Wood pulp and cotton lint are the main raw materials for producing viscose fiber. This wood pulps are undergoing through a purification process and obtained purified material contain about $95-99 \%$ of cellulosic polymer which are commonly known as chemical cellulose 
and dissolving pulp. These are used for producing regenerated fibers. In this paper, I described the details of viscose fiber properties and color fastness test methods.

\section{PHYSICAL PROPERTIES OF VISCOSE FIBER}

\section{Hydrophilic Property}

Viscose fiber is more hydrophilic in nature compared with cotton fiber where moisture content of cotton fiber is $8.5 \%$ at $27^{\circ} \mathrm{C}$ temperature and $65 \%$ of relative humidity, viscose fiber have moisture content $13 \%$ under the similar conditions.

\section{Elasticity}

Viscose fiber shows only $2-3 \%$ of elasticity. For this, during different stage of processing where tension applied on the viscose fiber need to be more aware to avoid unwanted tearing.

\section{Strength}

When viscose fiber gets wet it loses its strength too rapidly. In dry condition tensile strength of viscose fiber is $1.5-2.5$ $\mathrm{g} / \mathrm{denier}$, where in wet condition it is only $0.7-1.2 \%$.

\section{Elongation}

In general viscose fiber has an elongation at break is $15-30 \%$ but in case of high tenacity viscose fiber shows comparatively less about $10-18 \%$ only.

\section{Density}

There are various types of density found in viscose fiber such as $1.5 \mathrm{~g} / \mathrm{cc}, 3.0 \mathrm{~g} / \mathrm{cc}, 4.5 \mathrm{~g} / \mathrm{cc}$. Mostly available viscose fiber density is $1.53 \mathrm{~g} / \mathrm{cc}$.

\section{Effect of Temperature}

Viscose fiber loses its strength at $149^{\circ} \mathrm{C}$ temperature and start to decompose at $177^{\circ} \mathrm{C}$ to $205^{\circ} \mathrm{C}$.

\section{Effect of Light}

The ultraviolet rays of sunlight make the viscose fiber weak.

\section{Chemical Properties of Viscose Fiber}

As a regenerated fiber, Viscose has the more amorphous region in its construction. As a result its degree of polymerization is less than cotton fiber. So viscose fiber readily reacts with different chemicals like sulfuric acid, hydrochloric acid and decomposes cellulose as hydrocellulose.

\section{Effect of Acid}

The same concentration of Cotton fiber is less than acid. Inorganic acids are very harmful for viscose fiber but organic acid like acidic acid may use at low concentration below or equal $2 \%$.

\section{Effect of Soaping Agents}

Generally, soaping agent has not any significant effect on viscose fiber but improper soaping agent may cause bad odor and rancidity. 


\section{Effect of Heat}

Under the sunlight, the viscose fiber gradually losses its strength.

\section{Effect of Solvent}

Viscose has the solubility in cupramonium hydroxide. In other general solvents which are used as textile solvent cannot deteriorate.

\section{Effect of Ferrous Hydroxide}

Ferrous hydroxide weakens the viscose fiber. Any iron present in processing of viscose fiber may cause staining, rusting or any types of spots.

\section{Effect of Microorganisms}

Different microorganisms readily attack the viscose fiber. Most of the microorganisms attack at wet condition. Perfectly dried viscose generally not attacked by molds and mildew.

\section{Advantages of Viscose Fiber}

Viscose fabric absorbs dyes rapidly and uniformly. For this reason we easily obtain various types of shade, ton and hues. Viscose fiber gives very brighter shade. Its color last long with its life time and end user get better color fastness. It gives very smooth hand feel. For comfortable and colorful product anyone can confidently choose this fiber.

\section{Disadvantages of Viscose Fiber}

- Strength in wet condition is very poor.

- $\quad$ Need high degree of awareness during dyeing to avoid tearing.

- Need rapid dry otherwise various spots are appeared on the fabric surface.

- Correction of uneven shade depth is very difficult

- In every stage of processing temperature, pressure and tension need to properly maintain.

- Stripping reduces the strength significantly.

\section{Reactive Dyes}

The textile coloring substance which chemically reacts with the textile materials and being a part of the fiber by producing covalent bond with the fiber reactive group is called reactive dyes.

The chemical reaction takes place between the reactive group of dye particle and fiber molecule. Reactive dyes contain amino group. Normally, it makes covalent bond with hydroxide ion of cellulose.

\section{Application}

Reactive dyes can be used for dyeing

- Natural fiber: Cotton, wool, silk, Flax etc. cellulosic fibers

- Regenerated fiber: Viscose, Rayon, Modal etc.

- Synthetic fiber: Polyamide 
Trade Name

\begin{tabular}{|ll|ll|}
\hline a) & Sunzol Blue RS & a) & Sunfix Turquoise Blue G 266\% \\
\hline b) & Sunfix Scarlet S2G150\% & b) & Dianix Turquoise XF \\
\hline c) & Sunzol Black 6B & c) & Sunfix Turquoise 6B \\
\hline d) & Sunzol Red F3B & d) & Sunfix Green 6BT 133\% \\
\hline e) & Sunfix Navy Blue SBF & e) & Sunzol Green 6B \\
\hline f) & Sunfix Yellow S4GL 200\% & f) & Sunforn yellow SN-2R \\
\hline
\end{tabular}

\section{Properties of Reactive Dye}

- An anionic dye mostly used for cellulosic substance dyeing.

- $\quad$ Readily soluble in water.

- $\quad$ React with the fiber reactive group and forms covalent bond.

- $\quad$ Reactive dyes have UV protecting power.

- Better color fastness to light.

- Good color fastness to wash.

- Moderate color fastness to rubbing.

- Color fastness to perspiration is also good.

- $\quad$ It gives a wide range of shade verity.

- Comparatively cheap and available in market.

\section{General structure of Reactive Dyes}

Common structure of reactive dye can be expressed as, D-B-G-X.

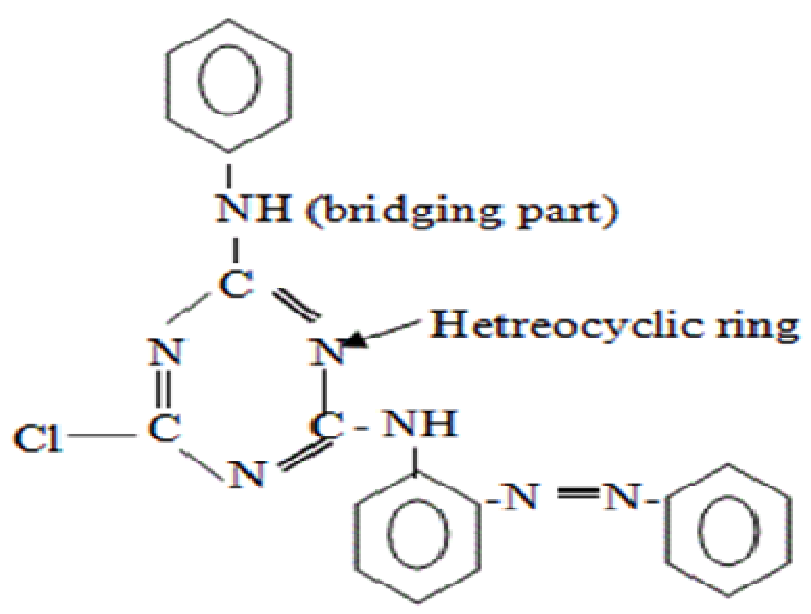

Figure 1: Chemical Structure.

Where,

$\mathrm{D}=$ Chromogen Color bearing unit.

$\mathrm{B}=$ Linker

Linker may be amino group or -NR group. 


$$
\begin{aligned}
& G=\text { Reactive group bearing unit } \\
& X=\text { Reactive group }
\end{aligned}
$$

\section{Dyeing Mechanism of Reactive Dye}

Dyeing procedure have been completed by three steps

- Exhaustion

- Fixation

- Reduction or washing out of unfixed dyes

Three steps are described below

\section{Exhaustion}

After immersion of textile material into the dye liquor, a salt is injected as an electrolyte for better exhaustion of dye particles on the fiber surface. Previously, we used $\mathrm{NaCl}$ but now-a-days we are using $\mathrm{MgSO}_{4}$ as an electrolyte.

\section{Fixation}

Fixation refers as the procedure of dye particle to be an integral part of textile material by reacting between fiber reactive group and dye molecule reactive group by forming covalent bond. For proper fixing strong alkali like caustic soda (NaOH) is added by dosing. At this stage proper $\mathrm{pH}$ should be maintained. The chemical reactions take place at this stage are shown below.

$$
\begin{aligned}
& \text { D- } \mathrm{SO}_{2}-\mathrm{CH}_{2}-\mathrm{CH}_{2}-\mathrm{OSO}_{3} \mathrm{Na}+\mathrm{OH}-\mathrm{Cell}=\mathrm{D}-\mathrm{SO}_{2}-\mathrm{CH}_{2}-\mathrm{CH}_{2}-\mathrm{O}-\mathrm{Cell}+\mathrm{NaHSO}_{3} \\
& \text { D-SO }-\mathrm{CH}_{2}-\mathrm{CH}_{2}-\mathrm{OSO}_{3} \mathrm{Na}+\mathrm{OH}-\mathrm{Wool}=\mathrm{D}-\mathrm{SO}_{2}-\mathrm{CH}_{2}-\mathrm{CH}_{2}-\mathrm{O}-\mathrm{Wool}+\mathrm{NaHSO}_{3}
\end{aligned}
$$

\section{Reduction}

After completing the dyeing process, a reduction cleaning with or without soaping agent is very essential to remove unfixed dye molecules from the surface of textile material. It may be a block wash or rinsing in hot condition or cold conditions. It is very essential for evenness and color fastness.

\section{Stripping of Reactive Dye}

Since the dye partials are chemically bonded with the fiber by strong covalent bond, it is very difficult to fully striped. Stripping is mainly of two types. They are

\section{Partial Stripping}

Partial stripping may carried out by processing the colored materials with dilute organic acid like acetic acid or formic acids. In this stage temperature raise up to $98^{\circ} \mathrm{C}$ and give run time until required amount of color come out of the solution. The recipe may be as following

Acetic acid: $6-10 \mathrm{~g} / 1$

Water: $1000 \mathrm{ml}$

Or Formic acid: $3-10 \mathrm{~g} / \mathrm{l}$

Water: $1000 \mathrm{ml}$ 
Temperature: $98^{\circ} \mathrm{C}$

Time: Generally 60 minutes

\section{Full Stripping}

Full stripping is very difficult in case of viscose fiber fabrics.

\section{Turquoise Color}

Turquoise is not any dyes actually it is one of the kinds of reactive dyes. It gives bluish or greenish ton and hue of color. The word invented from the French word “Turkish”. Normally shade appears fade bluish or faded green.
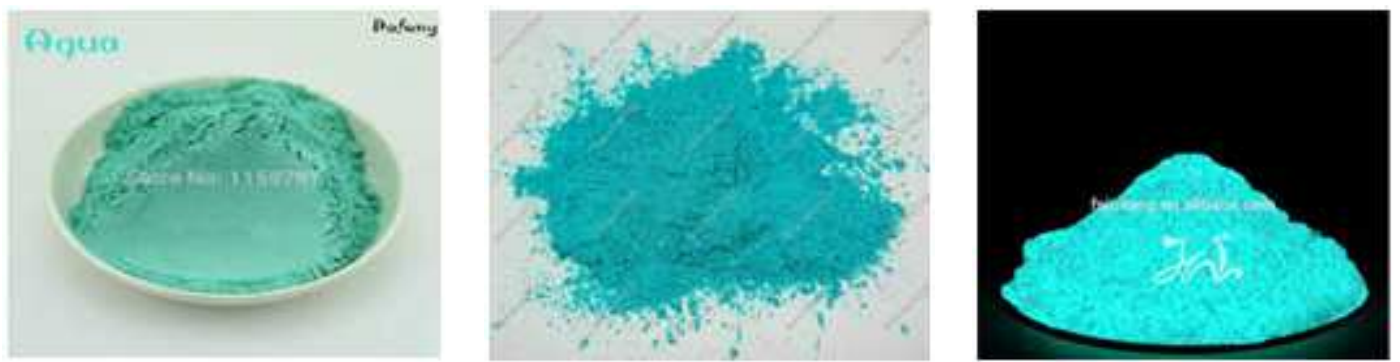

Figure 2: Solid Form of Turquoise Color.

\section{Process Flow Chart for Viscose Knit Fabric Dyeing With Reactive Dye (Turquoise Color)}

Water fills at $50^{\circ} \mathrm{C}$<smiles>[AlH2]</smiles>

Fabric loading at $50^{\circ} \mathrm{C}$

$\downarrow$

Viscobleach dosing $50^{\circ} \times 10^{\prime}$

$\downarrow$

Raise temperature $70^{\circ} \times 30^{\prime}$

$\downarrow$

Bath drop with rinsing

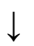

Fill water

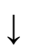

Acetic acid at $50^{\circ} \times 10^{\prime}$

$\downarrow$

Drain and rinse

$\downarrow$

Fill water at $50^{\circ} \mathrm{C}$

$\downarrow$

Rinse 5 Minutes

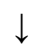

Drain

$\downarrow$ 
Fill water

$$
\downarrow
$$

$\mathrm{pH}$ check

$\downarrow$

Raise temperature up to $40^{\circ} \mathrm{C}$

$\downarrow$

Inject Levelling agent

Levegal RLC

$\downarrow$

Ronlube Plus C

$\downarrow$

Sequion 4898

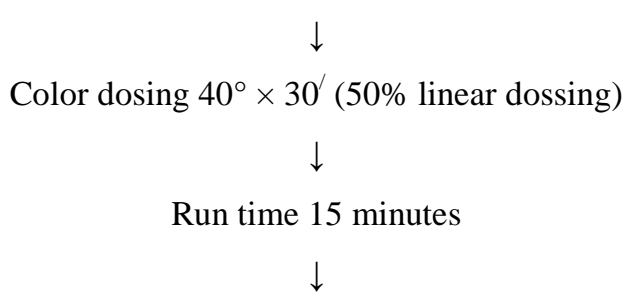

Salt dossing $40^{\circ} \times 20^{\prime}$

$\downarrow$

Raise temperature up to $85^{\circ} \mathrm{C}$

$\downarrow$

Run time 30 minutes

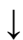

Cooling at $40^{\circ} \mathrm{C}$

$\downarrow$

$1^{\text {st }}$ time soda dossing $40^{\circ} \times 20^{\prime}$

(50\% Linear $2 \mathrm{~g} / \mathrm{L}$ )

$\downarrow$

Run time 5 minutes

$\downarrow$

Raise temperature up to $60^{\circ} \mathrm{C}(2 \%$ min $)$

$\downarrow$

Run time 10 minutes

$\downarrow$

$2^{\text {nd }}$ time soda dossing at $60^{\circ} \times 40^{\prime}$

(70\% progressive dossing)

$\downarrow$

Raise temperature up to $80^{\circ} \mathrm{C}$ 
Run time 10 minutes

$\downarrow$
Check pH
$\downarrow$
Color stream $60^{\circ} \times 60^{\prime}$
$\downarrow$
Shade check
$\downarrow$
Drain
$\downarrow$
Water fill
$\downarrow$
Wash at least 10 minutes
$\downarrow$
$\downarrow$
Rinsing with cold water
Drain
$\downarrow$

Water Fill

$\downarrow$

Wash 5 minutes

$\downarrow$

Drain

$\downarrow$

Fill cold water

$\downarrow$

Inject acetic acid at $40^{\circ} \mathrm{C}$

$\downarrow$

Neutralize 20 minutes

$\downarrow$

Drain

$\downarrow$

Fill water

$\downarrow$

Chimisperse RK \&sequion $4898\left(70^{\circ} \times 10^{\prime}\right)$

$\downarrow$

Raise temp at $95^{\circ} \&$ run time $10^{\prime}$

$\downarrow$

Cooling at $70^{\circ} \mathrm{C}$

$\downarrow$ 


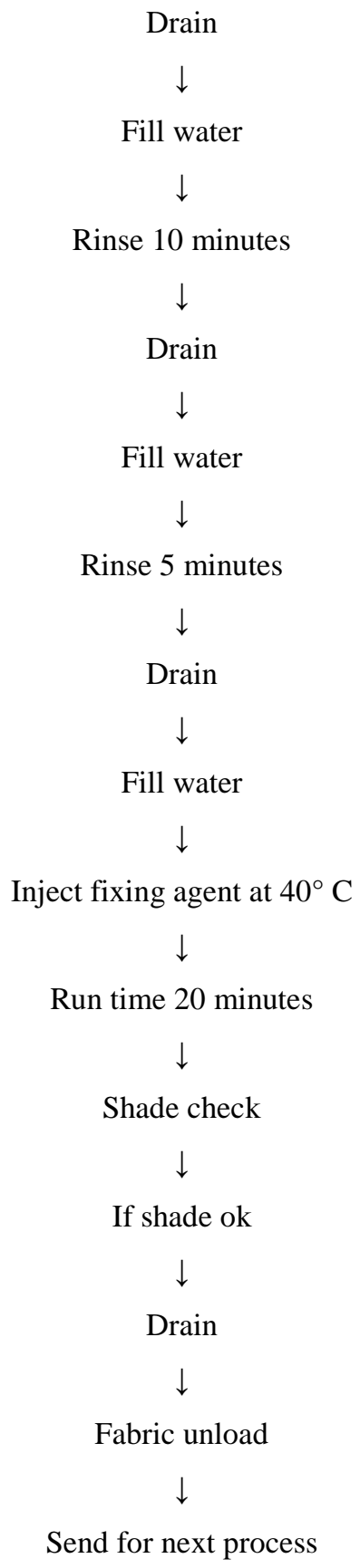

\section{Color Fastness}

Color fastness of textile dyed materials is a vital property. The end user customers are very aware about the color fastness of dyed materials. Color fastness means that the resistance of color to be bleed with others or fade of colored material both in printed or solid dyed to various kinds of influences like rubbing, perspiration, light, water, washing with detergents or others washing agents and others which phenomenon are carried out in daily basis with textile materials. We can easily get a large amount of paper for the color fastness.

\section{Standards of Color Fastness}

- American Association of Textile Chemist \& Colorist (AATCC). Origin America

- $\quad$ Society of Dyers \& Colorist (SDC). Origin Europe 
- International Organization for Standardization (ISO). This organization has two different scales for measuring colorfastness. One for the Color fastness to light and another is for color fastness to (wash, water, perspiration, rubbing etc.)

\section{Factors which Affect the Color Fastness}

- Chemical composition of the textile materials. Cellulosic fiber like cotton or viscose dyed with reactive dyes shows good colorfastness but any of synthetic fiber shows very poor color fastness if dyed with reactive dyes. Actually synthetic fiber will not adsorb the dye particle.

- Molecular size. In case of larger size of dye molecule, it will trap into intermolecular space of fiber very tightly and will show better color fastness.

- Physical form of dyes. It may be in liquid, paste or solid form. Different forms will show different color fastness.

- $\quad$ Shade Depth. Deeper the shade poorer the color fastness.

- Foreign agents.

- Condition of testing.

- The way of dye chemical to be the part of textile material. Such as if any chemical bonds form then the color fastness will be better rather than physically bonded materials. Covalent bond will show better than hydrogen bond.

\section{Measuring Scale}

There are two scale are available for measuring color fastness. Grey scale and wool blue scale.

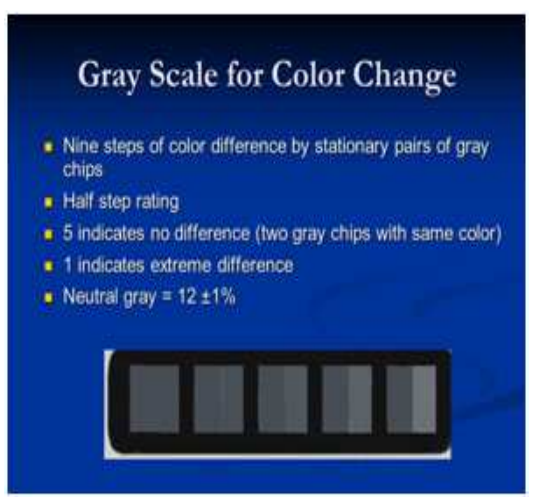

Figure 3: Gray Scale for Color Change.

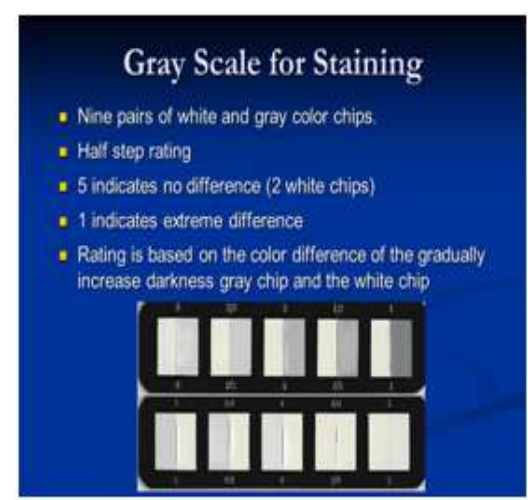

Figure 4: Gray Scale for Staining.

\section{Color Fastness to Washing}

The resistance of colored substance from bleeding or being faded when undergoing through the different washing process is known as color fastness to wash.

\section{Principle of Wash Fastness}

At first, we need to prepare a sample. Then the sample is attached with a multi-fiber fabric. Then wash under the specific condition. Then assessed the multi-fiber component for checking staining and match with the color fastness measuring scale for rating. 
Sample size should be $10 \mathrm{~cm} \times 4 \mathrm{~cm}$. This sample attached with same size of adjacent fabric to produce sandwich structure. One side of this specimen is stitched and subjected to wash under the specific condition. Color fastness to wash and we checked both color change and color staining. We used various washing procedure as shown in the Table 1.

Table 1: Different Washing Conditions

\begin{tabular}{|c|c|c|c|c|c|}
\hline Method & Wash Intensity & Alkali & Time in Minutes & Temperature & Still Ball \\
\hline ISO-687/79 & Very Mild (Hand Washing) & 5 & 30 & $40 \pm 2$ & 0 \\
\hline ISO-3361/79 & Five time bitter than previous one & 5 & 45 & $50 \pm 2$ & 0 \\
\hline ISO-764/79 & Mild wash & 7 & 30 & $60 \pm 2$ & 0 \\
\hline ISO-765/79 & Severe wash & 7 & 30 & $95 \pm 2$ & 10 \\
\hline ISO-341/79 & Severe wash & 7 & 240 & $95 \pm 2$ & 10 \\
\hline
\end{tabular}

For different methods solutions should be prepared by following the recommended temperature of washing for that method. The liquor ratio should be 50:1. After washing in recommended duration soaping is carried out. Then, wash with cold water and rinse 2 times. Finally, the Elements are dried at the recommended temperature which should not be more than $60^{\circ} \mathrm{C}$. That was evaluated with the gray scale.

\section{EVALUATIONS \& RESULTS}

Table 2: Evolution of Wash Fastness

\begin{tabular}{|c|c|l|}
\hline Shade Variation & Result & Comment \\
\hline $.5 \%$ & 5 & Excellent \\
\hline $1 \%$ & $4-5$ & Very good \\
\hline $1.5 \%$ & $4-5$ & Very good \\
\hline $2 \%$ & 4 & Good \\
\hline $2.5 \%$ & $3-4$ & Average \\
\hline
\end{tabular}

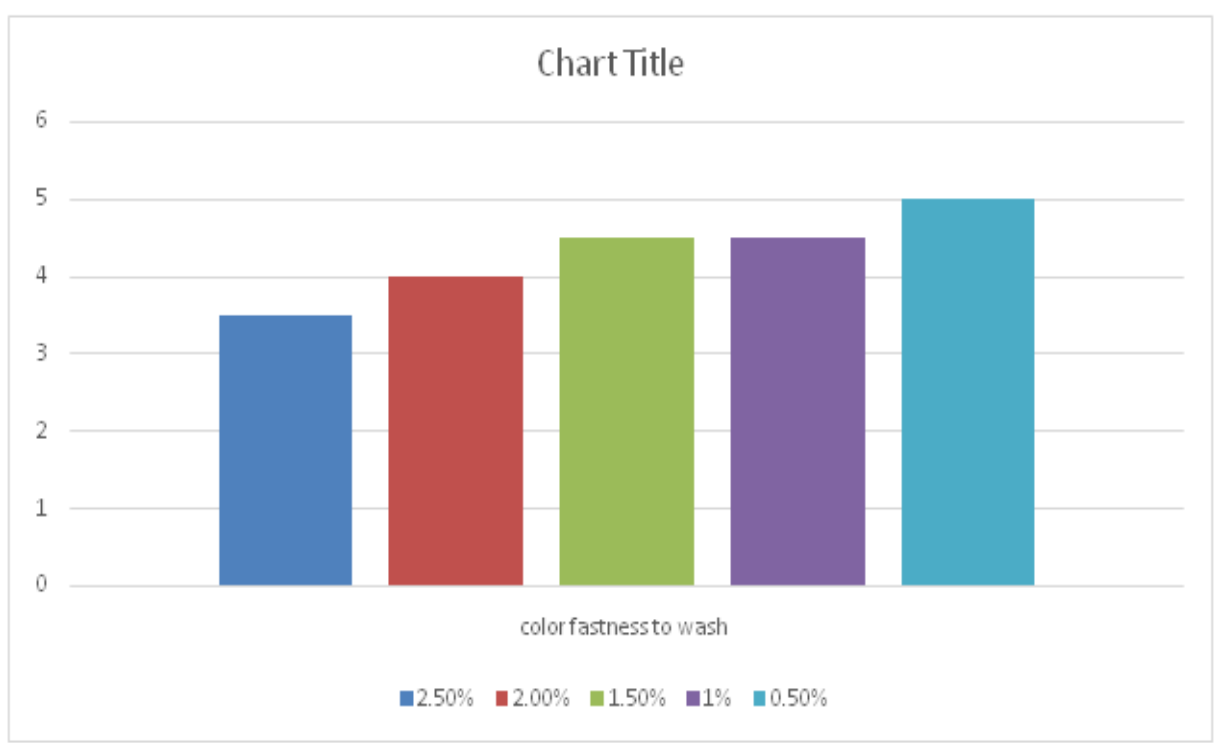

Figure 5: Histogram of Wash $F$ astness $C$ hange with $S$ hade $D e p t h$.

\section{Color Fastness to Water}

Resistance of color bleeding, staining or being fade of any dyed or printed material against water is called color fastness to water. Color fastness to water is measured by following principle of the method ISO 105 E01 or AATCC 107/1991. Actually, degree of staining is measured by this process when the textile material gets wet. 
This is an essential fastness for any types of textile material dyed with any type of dyes by any dyeing techniques. Instrument

- $\quad$ Sample specimen

- Multi-fiber fabric

- Glass beaker

- $\quad$ Stirring rod

- Glass Plate

- Perspiration meter

- $\quad$ Light box

- Gray Scale

- Dryer/oven

- Weight

\section{Reagent}

Distilled water is required to get actual result because natural water is contaminated with various metallic and nonmetallic irons.

\section{Sample Preparation}

$10 \mathrm{~cm} \times 4 \mathrm{~cm}$ sample has cut and sewing one side with multi-fiber fabric.

\section{Flow Chart of Task}

\section{Sample immerse in distilled water at room temperature}

$\downarrow$

Keep the sample on glass plate

$\downarrow$

Weight applied on the plate

$\downarrow$

Preserve in oven or dryer at $37 \pm 2^{\circ} \mathrm{C}$

$\downarrow$

Then take out of oven \& dried with hot air

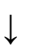

Temperature should not more than $60^{\circ} \mathrm{C}$

$\downarrow$

Evaluate result

\section{EVALUATIONS \& RESULTS}

Table 3: Evaluation of Color Fastness to Water

\begin{tabular}{|c|c|c|}
\hline Shade Variation & Result & Comment \\
\hline $.5 \%$ & 5 & Excellent \\
\hline $1 \%$ & $4-5$ & Very good \\
\hline
\end{tabular}




\begin{tabular}{|c|c|c|}
\hline \multicolumn{3}{|c|}{ Table 4: Contd., } \\
\hline $1.5 \%$ & $4-5$ & Very good \\
\hline $2 \%$ & 4 & good \\
\hline $2.5 \%$ & 4 & Good \\
\hline
\end{tabular}

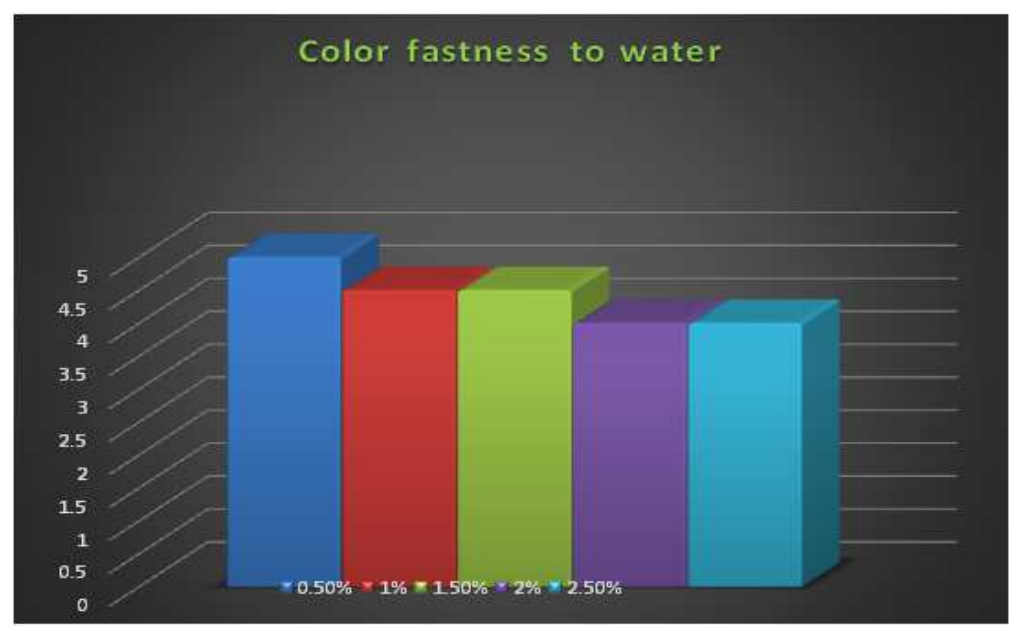

Figure 6: Graphical Representation of Color Fastness to Water.

\section{Rubbing Fastness}

When we wear a garment it is subjected to the friction with body and in different attack. If in this time color migrates to our body or other substance with which it goes friction it will not be acceptable. The resistance of color migration or staining due to rubbing with other substance is called color fastness to rubbing. Rubbing fastness generally measured in two conditions; wet and dry state.

\section{Methods of Rubbing Fastness Test}

- $\quad$ ISO $105 / \mathrm{X} 12$

- $\quad \mathrm{AATCC} / 08$

These two methods are about on same principle but different in wet pickup percentage. Hundred percentage wet pickup ensures ISO method. On the other hand only $65 \%$ wet pickup is enough for AATCC method. Rubbing fastness normally carried out in two conditions:

- Wet condition known as wet rubbing fastness.

- Dry condition known as dry rubbing fastness.

In case of wet rubbing test the rubbing material gets wet and then set with the finger of rubbing tester and carried out for 10-12 cycle of rub. In case of dry rubbing taste the whole method is similar to the wet rub just the dry abrading substance will be set with the finger of tester. Rubbing fastness actually shows the fixing quality of the dyes during coloration. Therefore, we can say better the color fastness to rubbing better the color fastness to wash and water.

\section{Factor Affecting Rubbing Fastness}

- $\quad$ Particle size: Larger the particle sizes better the rubbing fastness.

- $\quad$ Shade depth: Deeper the shade poorer the rubbing fastness. 
- Fabric construction: Different construction shows variation of rubbing fastness.

- Chemical composition of fiber.

- Nature of dyes and chemicals.

- Chemical bond produced during coloration (Dyeing or Printing).

\section{EVALUATIONS \& RESULTS}

Table 5: Evolution of Color Fastness to Rubbing

\begin{tabular}{|c|c|c|}
\hline Shade Variation & Result & Comment \\
\hline $.5 \%$ & $4-5$ & Very good \\
\hline $1 \%$ & 4 & Good \\
\hline $1.5 \%$ & 4 & Good \\
\hline $2 \%$ & $3-4$ & Average \\
\hline $2.5 \%$ & 3 & Average \\
\hline
\end{tabular}

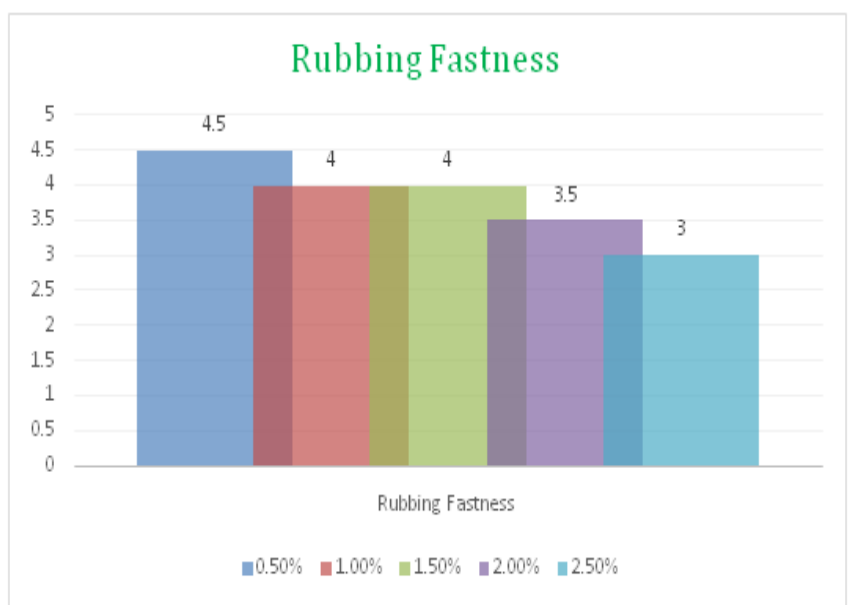

Figure 7: Graphical Representation of Color Fastness to Rubbing.

\section{Color Fastness to Light}

The light fastness can be defined as the resistance of color of any dyed or printed material from being fades when subjected to a light of specific wave length. After fully finished the material and prior to make garments in case of cut and sew garments color fastness to light observed via a testing method. When the user will come out from their residence, they come and expose to sunlight on the surface of the garments. Therefore, it is very much essential to know the resistivity of fading against sunlight of those materials. To ensure this quality of the product color fastness to light is measured and rated by comparing with blue scale.

\section{Principle of Color Fastness to Light}

Color fastness to light shows that the quality of product by which we can come to know about the stability of color against the exposure of light. At first, a sample prepared is kept under a continuous exposing of light source for 24-72 hours or any duration as per customer demand. Then take out from there and compare with the blue scale to rate how much it changed.

\section{Grading of Blue Scale}

Table 6: Grading of Blue Scale

\begin{tabular}{|c|c|c|}
\hline Rating & Amount of Fading & Comments \\
\hline 1 & Very Extensive Fading & Very poor \\
\hline 2 & Extensive Fading & Poor \\
\hline
\end{tabular}




\begin{tabular}{|c|c|c|}
\hline 3 & Significant Fading & Fair \\
\hline 4 & Appreciable or Enough Fading & Average/Moderate \\
\hline \multicolumn{3}{|c|}{ Table 7: Contd., } \\
\hline 5 & Average/ Moderate Fading & Good \\
\hline 6 & Slightly Fading & Very Good \\
\hline 7 & Very Slightly Fading & Excellent \\
\hline 8 & No Fading & Outstanding \\
\hline
\end{tabular}

\section{Light Fastness Test with Micro Sol Tester}

Working procedure of color fastness has completed by following steps

Prepare 4 pieces of sample

$\downarrow$

Sample attached with the sample holder

Then holder with sample set in arrangement of Light Fastness Tester

Keep the sample under light exposure from 24 to 72 hours

The specimen gets out from the tester

Compare exposed and unexposed sample with Blue scale

$\downarrow$

Rating by following Blue scale

\section{EVALUATIONS \& RESULTS}

Table 8: Evolution of Result of Color Fastness to Light

\begin{tabular}{|c|c|c|}
\hline Shade Variation & Result & Comment \\
\hline $.5 \%$ & 6 & Very good \\
\hline $1 \%$ & 5 & Good \\
\hline $1.5 \%$ & 5 & Good \\
\hline $2 \%$ & 4 & Average \\
\hline $2.5 \%$ & 4 & Average \\
\hline
\end{tabular}

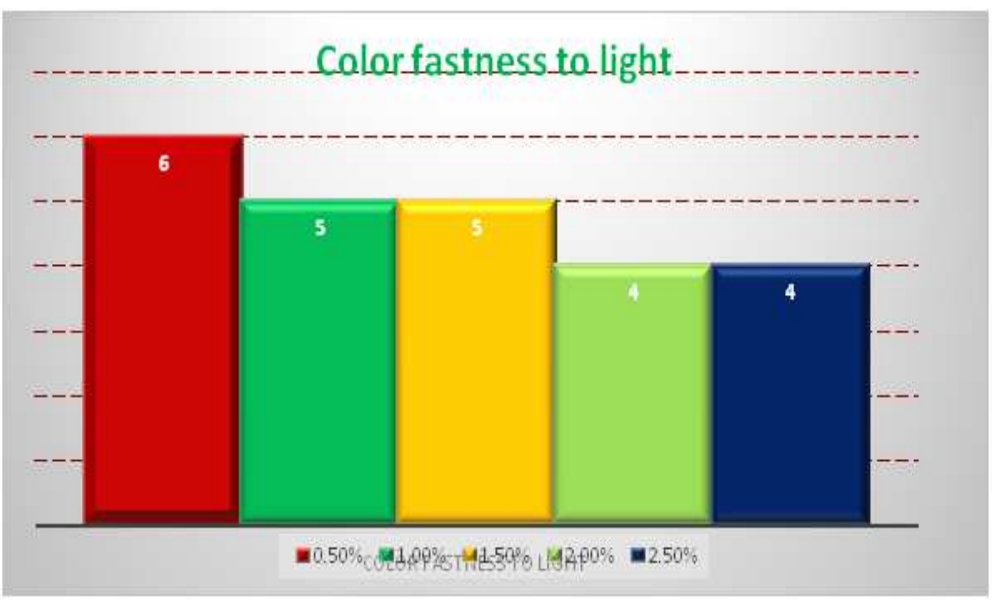


Figure 8: Graphical Representation of Color Fastness to Light.

\section{Color Fastness to Perspiration}

Perspiration test is essential for those products which are used for those of purpose where sweating probability high. The textile goods are used in household work like curtain, table cloth or any other decorative textiles. The items mostly used for sports need better quality against perspiration. Perspiration rating should be at least 3-4 according to the gray scale. Without sportswear normal clothes are also tested for color fastness to perspiration.

The resistance of color of any colored material solidly dyed or printed against the perspiration or sweat of the human body is called color fastness to perspiration. The sweat of the human body may be of two types acidic or alkaline. Both types of perspiration need to be tested. If the color of the garments come out with the sweating of the human body, it will be very annoying situation. Wet rubbing and wash fastness should be good prior to be good perspiration fastness good.

\section{Equipment Used for Perspiration Fastness Test}

- Sample which to be tested

- Light box

- Alkaline \& Acidic perspiration solution

- Glass plate

- Weight

- Multi Fiber Fabric (MMF)

- Oven

- Perspiration tester

- Gray Scale

\section{Reagent}

- 1-Histidine Mono Hydrochloride Mono Hydrate

- Sodium Chloride

- Disodium Hydrogen Orthophosphate

\section{Solution Preparation}

\section{Alkaline Solution}

About $0.5 \mathrm{~g}$ of 1-Histidine Mono Hydrochloride Mono Hydrate, $2.5 \mathrm{~g}$ of Disodium Hydrogen Orthophosphate and $5 \mathrm{~g}$ of Sodium Chloride are dissolved in $1 \mathrm{~L}$ of distilled water with $0.1 \mathrm{~N}$ caustic soda. The obtained solution will be alkaline in which the $\mathrm{pH}$ will be about 8.0 .

\section{Acidic Solution}

About $0.5 \mathrm{~g}$ of 1-Histidine Mono Hydrochloride Mono Hydrate, $2.2 \mathrm{~g}$ of Disodium Hydrogen Orthophosphate and $5 \mathrm{~g}$ of Sodium Chloride are dissolved in $1 \mathrm{~L}$ of distilled water with $0.1 \mathrm{~N}$ caustic soda. The obtained solution will be acidic in which the $\mathrm{pH}$ will be about 5.5. 


\section{Sample preparation}

A sample of $6 \mathrm{~cm} \times 6 \mathrm{~cm}$ is cut and sews with two same size of undyed cloth to produce composite sample for each and every solution.

\section{Working Procedure}

The perspiration test carried out by the following test procedure for two solutions separately.

Take the each of the solution

$$
\downarrow
$$

Completely immerse the sample into solution

$$
\downarrow
$$

At room temperature keep the solution 30 minutes

$$
\downarrow
$$

Take out the sample from solution and place between the glass plates

$$
\downarrow
$$

Apply weight $4.5 \mathrm{~kg}$ on the specimen

$$
\downarrow
$$

Keep in an oven at the temperature $37 \pm 2^{\circ} \mathrm{C}$ for four hours

\section{$\downarrow$}

Then take out from oven and removed the undyed fabric

$$
\downarrow
$$

Dried at not more than $60^{\circ} \mathrm{C}$

$$
\downarrow
$$

Evaluate the result with gray scale.

\section{EVALUATIONS \& RESULTS}

Table 9: Evolution of result of Color Fastness to Perspiration

\begin{tabular}{|c|c|c|}
\hline Shade Variation & Result & Comment \\
\hline $.5 \%$ & $4-5$ & Very good \\
\hline $1 \%$ & 4 & Good \\
\hline $1.5 \%$ & 4 & Good \\
\hline $2 \%$ & $3-4$ & Average \\
\hline $2.5 \%$ & 3 & Average \\
\hline
\end{tabular}




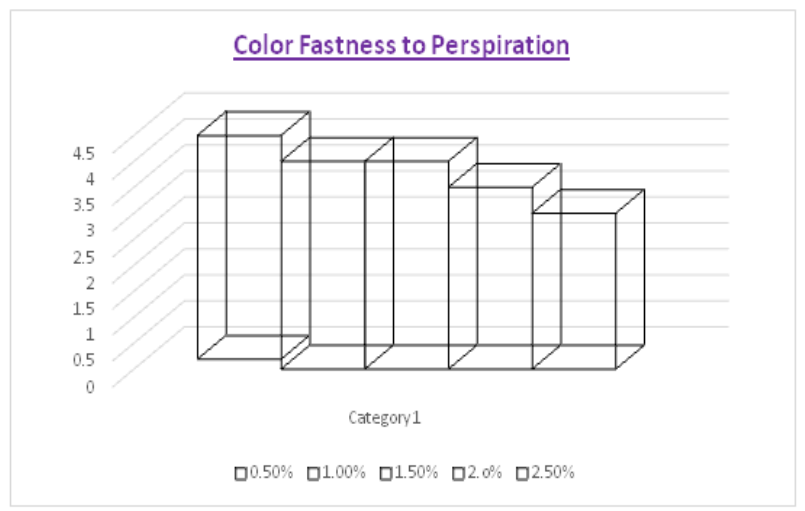

Figure 9: Graphical Representation of the Result of Color Fastness to Perspiration.

\section{CONCLUSIONS}

In this research we have studied on knitted viscose fabric dyed with reactive dye (Turquoise color). Fastness of colored material is essential for each and every goods which solidly dyed or printed. It refers the stability of color against various influences. Actually, comfort with quality is the crying demand now-a-days. At modern era no fabric can be delivered without better color fastness to various influences. In this study, the influence of the shade percentage on the color fastness to wash, to light, to rubbing, to water, to perspiration is investigated and evaluated. Results confirmed that the depth of the shade has a significant effect on the change of the color fastness properties. With the increase of the depth of the shade its color fastness performance decreases.

\section{ACKNOWLEDGEMENTS}

This research carried out by the cooperation and ascertainment of each authors. The whole report is assessed by every authors and our guide supervisor. We really would like to humbly thanks and honor to all the members of Epyllion Group for their cooperation and increasing enthusiasm for completing this research paper.

\section{REFERENCES}

1. Study of C.I. Reactive Yellow 145, C.I. Reactive Red 238 and C.I. Reactive Blue 235 dyestuffs in order to use them in color formulation. Part 2: modeling and optimization of dyeing performances.

2. The Effect of Temperature Variation on Dyeing Tie-Dye viscose Fabrics Dyed with Reactive Dye.

3. Chemical cationization of cotton fabric for improved dye uptake. Cellulose.

4. Aspland, J.R., Textile Dyeing and Coloration. Textile Hub 2006. 1(3): p. 265-274.

5. Nithyanandan, R. and M. Subramanian, Salt\& Alkali Free Reactive Dyeing.

6. Broadbent and A.D, Basic Principle of Textile Coloration. A.S.T.M, 2001. 1(2): p. 337.

7. https://www.britannica.com/technology/dye

8. Textile Dyeing and Printing Technology.

9. www.slideshare.com

10. www.dinetextile.blogpost.com

11. Textilelearner.blogpost.com 